\title{
Comparison of Core Endurance and Hamstring Flexibility of Adults with and without Low Back Pain
}

\author{
Heta D Baxi ${ }^{1}$, Megha S Sheth ${ }^{2}$ \\ ${ }^{1} 2^{\text {nd }}$ Year PG, Community Health and Rehabilitation, SBB College of Physiotherapy, Ellisbridge, \\ Ahmedabad-380006 \\ ${ }^{2}$ Lecturer, Community Health and Rehabilitation, SBB College of Physiotherapy, Ellisbridge, \\ Ahmedabad-380006 \\ Corresponding Author: Heta D Baxi
}

\begin{abstract}
Introduction: Reduced endurance of trunk muscles as well as poor hamstring flexibility have been found in subjects with backache. Few studies have explored the variations in core endurance and hamstring flexibility in non-athlete subjects with low back pain and normal individuals in Indian community at large. This study aims at comparing the core endurance and hamstring flexibility of the healthy individuals and subjects with low back pain.

Method: This cross-sectional study was conducted in physiotherapy department and community of Ahmedabad. Males and females of 18-65 years with low back pain of any duration and cause were included in Group: A. Subjects with acute/severe back pain where core endurance tests would flare up the pain, diagnosed psychiatric illness, neurological conditions, rheumatic diseases were excluded. Group B had subjects with no back pain. Exclusion criteria were the same for Group: B. Core endurance was assessed with McGill's core endurance test. Hamstring flexibility was assessed using Sit and reach test. Comparison between the two groups was done using Mann Whitney test and t-test respectively.

Results: Total 101 subjects were approached for the study out of which 96 participated in the study. Statistically significant difference was found between the core endurance $[U=563.5, p<0.001$ for trunk flexor endurance; $U=294.5, p<0.001$ for trunk extensor endurance $U=573.0, p<0.001 ; U=522.0$, $\mathrm{p}<0.001$ for trunk side bridge test (right and left respectively)] and hamstring flexibility $(\mathrm{t}=-3.063$, $\mathrm{df}=94 ; \mathrm{p}=0.003$ ) in persons with and without low back pain.
\end{abstract}

Conclusion: There is a significant difference in core endurance time and hamstring flexibility in subjects with and without LBP.

Keywords: Low back pain; Core endurance; sit and reach test; muscle tightness; flexibility.

\section{INTRODUCTION}

The term Low back pain (LBP) refers to a pain of variable duration in an area of the anatomy afflicted so often that it is has become a paradigm of responses to external and internal stimuli. Low back pain is pain, muscle tension, or stiffness localised below the costal margin and above the inferior gluteal folds, with or without leg pain (sciatica), and is defined as chronic when it persists for 12 weeks or more. It is an extremely common problem that most people experience at some point in their life. ${ }^{[1]}$ It may occur due to involvement of the vertebral bodies, intervening discs, ligaments, muscles, nerves, or other structures in the spine. The pain may be constant or intermittent, experienced in one site or radiating to other areas. ${ }^{[2]}$ Nearly $60 \%$ of the people in India have suffered 

pain.

from LBP at some time during their lifespan. ${ }^{[3]}$

The major source of spinal stability arises from the activation and endurance of the core musculature. The core is a 3 dimensional space with diaphragm (superior), abdominal and oblique muscles (anterior-lateral), paraspinal and gluteal muscles (posterior), and pelvic floor and hip girdle (inferior) as its muscular boundaries. [4],[5] Panjabi and Crisco demonstrated the critical role of muscles in core stability. Panjabi's model of core stabilization included 3 inter-dependent subsystemsPassive subsystem (Ligaments, capsules, IV disc, passive properties of muscle),Active subsystem (core musculature which provides dynamic stabilization to the spine and proximal appendicular skeleton, as well as movement information to the neural control subsystem),Neural control subsystems (centre for incoming and outgoing signals that ultimately produce and maintain core stability) (Figure:1) Studies suggest that low core endurance holding times is a risk factor for LBP and reduced endurance of trunk muscles have been found in subjects suffering from backache. ${ }^{[6],[7]}$ McGill's torso endurance battery tests have been used to evaluate the isometric core endurance and have been found to be reliable. ${ }^{[8],[9]}$

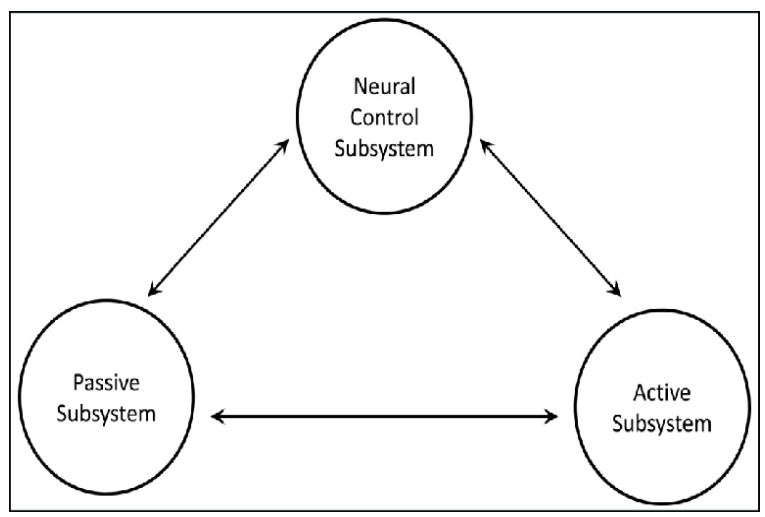

Figure: 1 Spinal stability model proposed by Panjabi

Hamstring shortness can influence pelvic dynamics thereby affecting the trunk movements adopted by subjects during various occupational activities. Movement restrictions can reduce the capacity to obtain appropriate postural responses. Due to this, low back pain may occur in occupations with sustained mal-adapted posture or repetitive load on a specific spinal segment ${ }^{[10]}$. Fasuyi et al found that hamstring muscle length was significantly reduced in participants with low back pain. Pelvic tilt range reduces as hamstring length increases [11]. Poor hamstrings flexibility has been associated with low back pain in crosssectional studies in both adolescents and adults ${ }^{[12]-[13]}$. The sit and reach test is an acceptable measure for measuring hamstring flexibility of young, middle-aged, and older men and women. ${ }^{[14],[15]}$

Core endurance and strengthening exercises have been a part of low back pain treatment protocol since a long time. The role of hamstring tightness as a factor responsible for causing LBP is controversial. Since there are few studies conducted comparing the core endurance and hamstring flexibility in non-athlete subjects with low back pain and normal non athlete individuals in Indian community at large, this study aims to assess and compare the core endurance and hamstring flexibility of young and middle aged adults with and without LBP.

\section{MATERIALS AND METHODS}

The observational, analytical crosssectional study was conducted in the orthopaedic department of the Physiotherapy College and Community of Ahmedabad for 1 year. Ethics approval was taken from Institutional Review Board (PTC/IEC/29/2019-20). Written informed consent was taken from all the subjects after explaining the study. Sample size obtained was 96 and data collection was done using convenience sampling. For subjects with low back pain (Group: A), males and females of ages between 18 to 65 years with low back pain of any duration with or without radiation, irrespective of the cause (except the ones in exclusion criteria) were included in the study. Subjects with acute/Severe low back pain where core endurance tests will flare the pain, 

pain.

diagnosed psychiatric illness (depression, mania etc.), neurological conditions (hemiplegia, poliomyelitis), rheumatic diseases (Rheumatic Arthritis, Ankylosing Spondylitis) were excluded. For healthy individuals without low back pain (Group: B)-Inclusion criteria was males and females of ages between 18 to 65 years; exclusion criteria was kept same as Group: A. Demographics included name, age, gender, time duration for low back pain, smoking history, marital status, socio-economic status (taken by modified Kuppuswamy scale 2019).McGill core endurance test and sit and reach test were performed as follows:

\section{McGill's core endurance tests} (Figures: 1-4)

For McGill's torso endurance battery, a maximum of 2 trials per patient was given. Best of two trials was taken as the endurance score. For each of the core endurance tests, the test was terminated if the subject was unable to hold the position/ was uncomfortable or when the therapist noticed a significant deviation in the patient position.

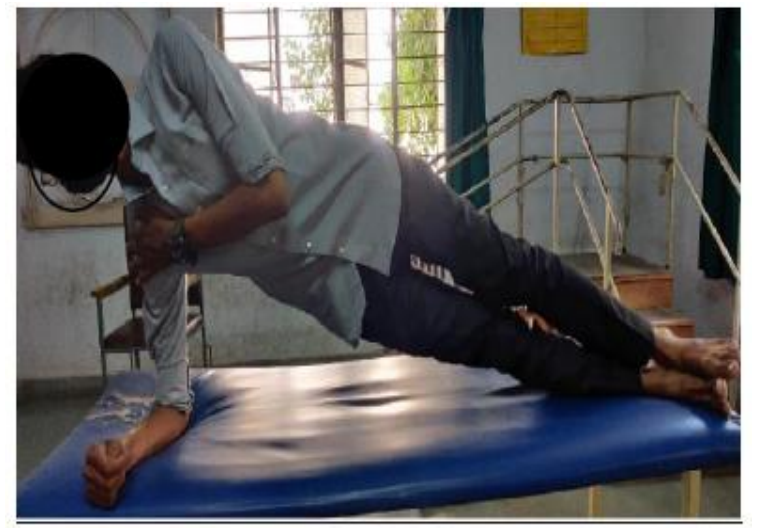

Figure: 1 Trunk side bridge test

At the start of the test, each subject was in the side-lying position. The legs were kept extended. Participants supported themselves on the elbow and the feet. They were asked to lift their hip off the bed and maintain a straight line with the whole body throughout the test using only their feet and lower elbow for support. The uninvolved arm was held across the chest with the hand resting on the opposite shoulder. The test was terminated when the subject was unable to maintain the position or was uncomfortable or had pain. The test was repeated on the opposite side and time was recorded.

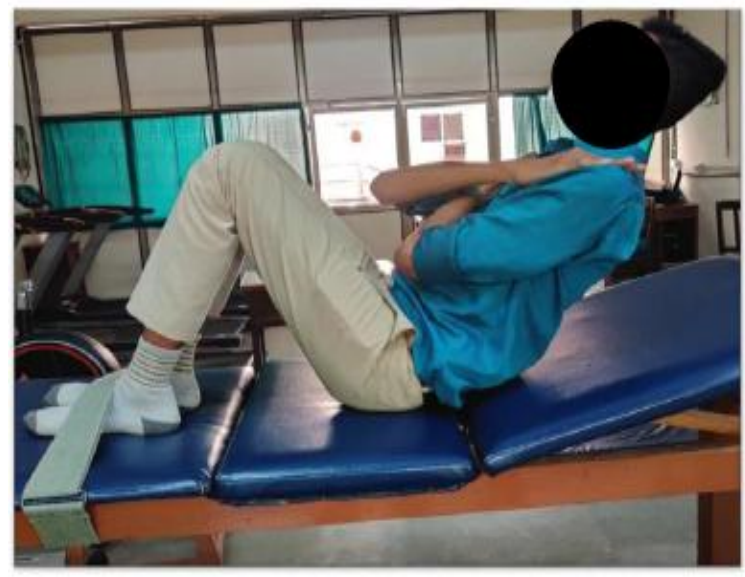

Figure: 2 Trunk flexor endurance test

The starting position for the trunk flexor endurance test involved positioning the subjects on a plinth with their back resting against a wedge that maintains 60 。 flexion from the horizontal. Knees were flexed to $90^{\circ}$ and the feet were secured with a seat belt. To begin, the support was removed back $10 \mathrm{~cm}$ and the participant was asked to hold the body position as long as possible. The test was terminated when there was a noticeable change in the trunk position: a deviation from the neutral spine (i.e., the shoulders rounding forward) or an increase in the low-back arch or if patient grew uncomfortable or had increased pain. No part of the back touched the back rest. Time was recorded.

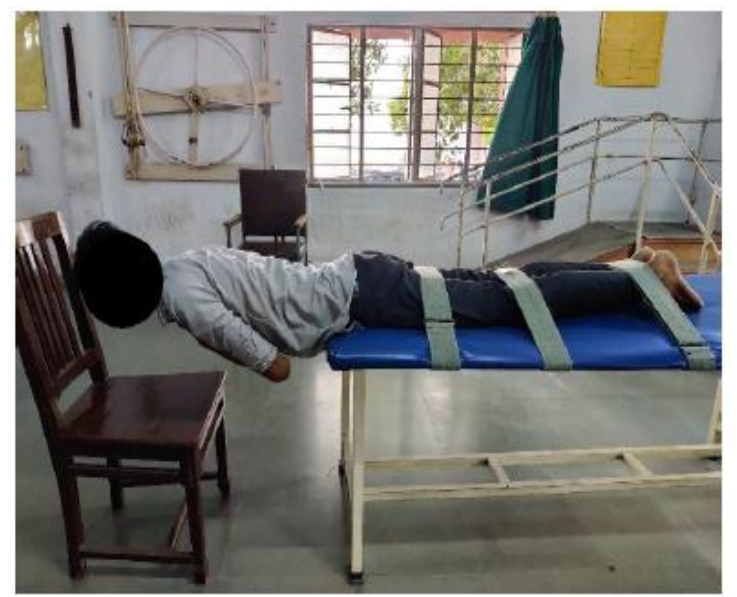

Figure:3 Trunk extensor endurance test (Biering-Sorenson Test) 

pain.

The subject was positioned prone on a treatment couch with the lower half of the body below the level of the anterior superior iliac spines strapped to the couch at three positions: at the ankles as close to the malleoli as possible, at the knee creases, and at the level of the greater trochanter of the femur. The stabilization belts were tightened as firmly as possible while considering the subject's level of comfort. Before beginning the test the subject was allowed to rest the top half of the body on a chair. The subject was then told that at the beginning of the test he or she would be required to lift the upper trunk clear of the chair, place the arms across the chest and maintain the trunk in neutral alignment for as long as possible. Criteria for termination of the test: Subject terminated the test because of excessive fatigue, if pain or other symptoms become too great, and rater terminated the test if the subject did not maintain the upper trunk in neutral.

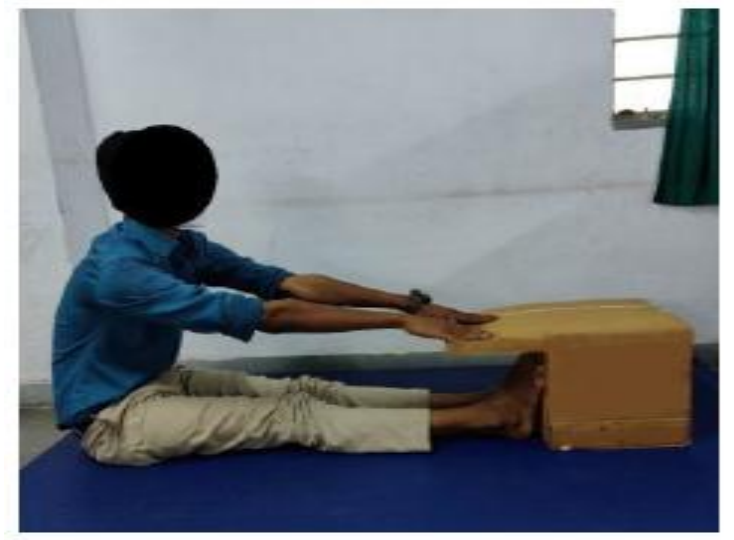

Figure: 4 Sit and reach test

A sit and reach box was made with the zero mark at $23 \mathrm{~cm} .{ }^{1}$ To begin the test, the subject sat on the floor with both feet straight out against a box for them to press their feet against it. Both knees were pressed down to the floor. With the palms facing downwards, and the hands side by side, the subject bobbed forward four times and held the position of maximum reach on the fourth count. The subject was asked to maintain the position for 2 counts. The most distant line touched by the fingertips of both hands was noted and distance was measured in $\mathrm{cm}$. If the hands reach unevenly, the hand reaching the shorter distance determined the score. The score was taken to the nearest centimetre line. If the reach appeared to be exactly half-way between two lines, the score was based on the last line actually touched.

Statistical analysis: Analysis was done using SPSS v20 and Microsoft Excel 2013.The normality of the data was tested using Kolmogorov-Smirnov test for nonparametric distribution.(p <0.05). Comparison of the core endurance between the two groups was done using Mann Whitney $U$ test for non-parametric distribution. Comparison of the Sit and reach test was done using student's t-test for independent samples. Confidence level was kept at $95 \%$.

\section{RESULTS}

Total 101 subjects were approached for the study out of which 96 participated in the study (50 in Group A, 46 in Group B). Five patients were eliminated from Group: A as they had acute severe back pain. Age was $37.14 \pm 10.10$ years (Mean \pm SD) for Group: A and $30.70 \pm 11.57$ years (Mean \pm SD) for Group: B. Group: A had 20 males and 30 females while Group: B had 7 males and 39 females. The demographic details of the patients are as shown in Table: 1. The core endurance measured in seconds and distance reached (in $\mathrm{cm}$ ) during the sit and reach test for Group: A and B are as follows (Table: 2 and 3)

Table: 1 Demographic data of Group: A and Group: B

\begin{tabular}{|c|c|c|}
\hline Demographics & Group: A & Group: B \\
\hline Occupation & \multirow{4}{*}{$\begin{array}{l}22 \\
27 \\
01\end{array}$} & \multirow{4}{*}{$\begin{array}{l}39 \\
07 \\
01\end{array}$} \\
\hline Working & & \\
\hline Housewife & & \\
\hline Others & & \\
\hline Socioeconomic status & \multirow{6}{*}{$\begin{array}{c}01 \\
06 \\
14 \\
22 \\
09\end{array}$} & \multirow{6}{*}{$\begin{array}{c}29 \\
05 \\
02 \\
09 \\
01\end{array}$} \\
\hline Upper (I) & & \\
\hline Upper Middle (II) & & \\
\hline Lower Middle (III) & & \\
\hline Upper Lower (IV) & & \\
\hline Lower $(\mathrm{V})$ & & \\
\hline Anthropometric measures & \multirow{4}{*}{$\begin{array}{l}(\text { Mean } \pm \text { SD) } \\
1.59 \pm 0.08 \\
62.06 \pm 11.48 \\
24.61 \pm 4.42\end{array}$} & \multirow{4}{*}{$\begin{array}{l}\text { (Mean } \pm \text { SD) } \\
1.61 \pm 0.09 \\
56.91 \pm 9.44 \\
22.16 \pm 4.11\end{array}$} \\
\hline Height $(\mathrm{m})$ & & \\
\hline Weight (kg) & & \\
\hline BMI $\left(\mathrm{kg} / \mathrm{m}^{2}\right)$ & & \\
\hline Time duration for $\mathrm{LBP}$ & \multirow{4}{*}{$\begin{array}{l}28 \\
06 \\
16\end{array}$} & \multirow{4}{*}{$\begin{array}{l}- \\
- \\
-\end{array}$} \\
\hline $1-6$ months & & \\
\hline $7-12$ months & & \\
\hline$>12$ months & & \\
\hline
\end{tabular}



pain.

Table: 2 Mean holding time of core endurance tests of Group: A and Group: B

\begin{tabular}{|l|l|l|}
\hline $\begin{array}{l}\text { Core } \\
\text { endurance tests }\end{array}$ & $\begin{array}{l}\text { Holding time in } \\
\text { seconds for Group: } \\
\text { A (Mean } \mathbf{\text { SD}} \text { ) }\end{array}$ & $\begin{array}{l}\text { Holding time in } \\
\text { seconds for Group: } \\
\text { A (Mean } \pm \text { SD) }\end{array}$ \\
\hline $\begin{array}{l}\text { Trunk Flexor } \\
\text { endurance }\end{array}$ & $16.38 \pm 10.94$ & $41.17 \pm 36.3$ \\
\hline $\begin{array}{l}\text { Trunk Extensor } \\
\text { endurance }\end{array}$ & $7.43 \pm 4.33$ & $26.57 \pm 20.53$ \\
\hline $\begin{array}{l}\text { Trunk Side } \\
\text { Bridge test } \\
\text { (Right) }\end{array}$ & $8.14 \pm 5.76$ & $19.36 \pm 16.56$ \\
\hline $\begin{array}{l}\text { Trunk side } \\
\text { Bridge test (left) }\end{array}$ & $6.16 \pm 5.78$ & $16.67 \pm 12.2$ \\
\hline
\end{tabular}

Table: 3 Mean score of sit and reach test for Group: A and Group: B

\begin{tabular}{|l|l|}
\hline Sit and reach test \\
\hline Distance reached (in cm) by Group: A (Mean \pm & $22.26 \pm$ \\
SD) & 7.22 \\
\hline Distance reached (in cm) by Group: B (Mean \pm & $27.04 \pm$ \\
SD) & 8.09 \\
\hline
\end{tabular}

Core endurance was compared using Mann Whitney U test. Significant difference was found between both the groups. (Table:4)

Table:4 Comparison between core endurance holding time; distance reached in sit and reach test using Mann Whitney and t-test respectively

\begin{tabular}{|c|c|c|c|}
\hline Variable & \multicolumn{3}{|c|}{ Mann Whitney Test } \\
\hline & Mean rank & U-value & p-value \\
\hline $\begin{array}{l}\text { Trunk Flexor } \\
\text { Endurance }\end{array}$ & $\begin{array}{l}\text { Group: } \mathrm{A}=36.77 \\
\text { Group: } \mathrm{B}=61.25\end{array}$ & 563.5 & 0.00 \\
\hline $\begin{array}{l}\text { Trunk Extensor } \\
\text { Endurance }\end{array}$ & $\begin{array}{l}\text { Group: } \mathrm{A}=31.39 \\
\text { Group: } \mathrm{B}=67.10\end{array}$ & 294.5 & 0.00 \\
\hline $\begin{array}{l}\text { Trunk Side Bridging } \\
\text { (Right Side) }\end{array}$ & $\begin{array}{l}\text { Group: } \mathrm{A}=36.96 \\
\text { Group: } \mathrm{B}=61.04\end{array}$ & 573.0 & 0.00 \\
\hline \multirow[t]{3}{*}{$\begin{array}{l}\text { Trunk Side Bridging } \\
\text { (Left Side) }\end{array}$} & $\begin{array}{l}\text { Group: } \mathrm{A}=35.94 \\
\text { Group: } \mathrm{B}=62.15\end{array}$ & 522.0 & 0.00 \\
\hline & \multicolumn{3}{|l|}{ Student's t-test } \\
\hline & t-value & df & p-value \\
\hline Sit and reach test & -3.063 & 94 & 0.003 \\
\hline
\end{tabular}

\section{DISCUSSION}

The present study shows that there is a statistically significant difference between the mean core endurance time of persons with low back pain and normal healthy individuals for trunk flexor endurance $(\mathrm{U}=563.5, \quad \mathrm{p}<0.001), \quad$ trunk extensor endurance $(\mathrm{U}=294.5, \mathrm{p}<0.001)$, trunk side bridge test (right side) $(\mathrm{U}=573.0, \mathrm{p}<0.001)$, trunk side bridge test (left side) (U=522.0, $\mathrm{p}<0.001)$. There is a statistically significant difference between the distance reached for the sit and reach test $(\mathrm{t}-\mathrm{value}=-3.063$, df $=94, \mathrm{p}=0.003$ ).

Many studies have found significant difference between the core endurance of individuals with and without low back pain. [18],[19] Fang Liu et al found the trunk endurance of Chinese adults in the age group 20-59 years using Biering-Sorenson test, Side bridge test, plank test. From 188 participants, 16 had low back pain. No significant difference was found in the trunk endurance of participants with and without low back pain. ${ }^{[20]}$ The current study had found statistically significant difference in all the trunk endurance holding time. Ethnic differences may be responsible for it. ${ }^{[21]}$ When compared with Chinese and European men, at any given body fat mass value, South Asians have significantly less lean mass than each of the three other groups after adjustment for age, height, humerus breadth, smoking status, physical activity, and diet. Similarly, F: LM (fat: lean mass) ratio is higher in South Asian men and women. ${ }^{[22]}$

JJ Dawes et al in a retrospective cohort study found that for measures of aerobic fitness, FM(fat mass) may be of greater predictive importance than LM (lean mass) and, conversely, for measures of strength and muscular endurance (like bench press, peak power and push-ups), LM may be more important than FM. ${ }^{[23]}$ Pedro Correia et al analysed the differences in trunk endurance time, fatigue and activation in 35 tennis players with and without low back pain using McGill endurance tests and found significant differences between trunk flexor and right side bridge endurance time. ${ }^{[24]}$ Core musculature weakness itself is a significant contributor of LBP as it may cause abnormal loading on the vertebra, causing altered biomechanics which may lead to sprain, strain or overloading. Similarly stain/sprain or trauma to the back muscles cause pain which leads to reduced use or activation of the particular set of muscles, causing atrophy and giving rise to the pain-weakness-pain cycle. Reduced modulation of TrA muscle thickness along with decreased EMG activity in TrA muscle during isometric leg tasks as well as reduced thickness of lumbar multifidus, internal obliques have been found in back pain patients. ${ }^{[25]-[27]}$ A.F. Mannison et al found significant higher proportion of type 2 
muscle fibres (fast twitch, glycolytic) in paraspinal muscles in subjects with LBP. ${ }^{[28]}$ Thus, altered neuromotor control, greater proportion of fast twitch muscle fibres in postural control muscles which leads to increased fatigability and reduced cross sectional area of core muscles are some of the significant factors responsible for decreased endurance in patients with LBP.

There is a statistically significant difference $(\mathrm{t}=-3.063$, df $=94, \mathrm{p}=0.003)$ in the hamstring flexibility of the subjects with and without LBP. Amir Massaoud Arab et al investigated the relation between hamstring muscles length and lumbar lordosis in individuals with different lifestyle and work setting. A significant difference was found in the hamstring muscle length of persons with and without low back pain, however no significant difference in lumbar lordosis was found in individuals with and without hamstring tightness in normal and LBP subjects with different work setting and lifestyle. [29] Mistry Gopi et al assessed hamstring tightness in subjects with chronic back pain and normal individuals using the active knee extension test (AKE) and found that hamstring tightness is present in subjects with LBP. ${ }^{[30]}$ A systemic review with metaanalysis conducted by Masakata Hori et al was inconclusive if hamstring tightness and stiffness was associated with low back pain as the quality of evidence was low. [31] Hamstring muscles are mobilizers which in general have a tendency to be more active than the stabilizer muscles. As hamstring originates from ischial tuberosity and has insertion at tibia and fibula, it contributes to pelvic, hip and knee motion. Hence, tight hamstring limits pelvic motion which in turn places increased load on the lax spinal tissues. ${ }^{[10]}$ Shear modulus of all 3 hamstring muscles (Semimembranosus, semitendinosus, Biceps femoris) was found to be negatively correlated with sit and reach scores i.e. Higher the shear modulus, lower the sit and reach scores. ${ }^{[32]}$ Thus, hamstring tightness and over activity can contribute to LBP. This finding is in agreement with the present study where a difference in the scores of sit and reach test was found between subjects having LBP and individuals without LBP with lower scores in subjects with LBP.

\section{CONCLUSION}

The present study concludes that a significant difference exists in the core endurance and hamstring flexibility of subjects with LBP and those without it. The current study has certain limitations. Due to Covid-19 pandemic, homogenous stratification of the subjects could not be done. Trunk flexor: extensor ratio has not been calculated. Regression analysis has not been done for the variables. There is a need to include the core endurance assessment in the patients suffering from low back pain irrespective of the time duration, presence of radiculopathy and the onset. Hamstring tightness must be addressed while evaluating any patient with low back pain. Further research is required to understand the exact role of core endurance, hamstring flexibility and the relationship between these variables with respect to LBP.Future recommendations include establishing normative data of trunk endurance of Indian population .Trunk endurance of Indian population if known, can help predict the low back pain and appropriate ergonomic advices and exercise protocols can be useful in prevention of back pain.

\section{Acknowledgement: None}

\section{Conflict of Interest: None}

\section{Source of Funding: None}

\section{Ethical Approval: Approved}

\section{REFERENCES}

1. Chou R. Low back pain (chronic). BMJ clinical evidence. 2010;2010.

2. NazeerM,RaoSM,SoniS,RavinderM,Ramakr anthiT, Bhupathi S. Low back pain in south Indians: Causative factors and preventive measures. Sch J Appl Med Sci 3(1D): 234243, 2015. 
3. Koley S, Sandhu NK. An association of body composition components with the menopausal status of patients with low back pain in Tarn Taran, Punjab, India. Journal of Life Sciences. 2009 Dec 1;1(2):129-32.

4. Akuthota V, Nadler SF. Core strengthening. Archives of physical medicine and rehabilitation. 2004 Mar 1;85:86-92.

5. Huxel Bliven KC, Anderson BE. Core stability training for injury prevention. Sports health. 2013 Nov;5(6):514-22

6. Swain C, Redding E. Trunk muscle endurance and low back pain in female dance students. Journal of Dance Medicine \& Science. 2014 Jun 15;18(2):62-6.

7. del Pozo-Cruz B, Gusi N, Adsuar JC, del Pozo-Cruz J, Parraca JA, HernandezMocholí M. Musculoskeletal fitness and health-related quality of life characteristics among sedentary office workers affected by sub-acute, non-specific low back pain: a cross-sectional study. Physiotherapy. 2013 Sep 1;99(3):194-200.

8. Abdelraouf OR, Abdel-aziem AA. The relationship between core endurance and back dysfunction in collegiate male athletes with and without nonspecific low back pain. International journal of sports physical therapy. 2016 Jun;11(3):337.

9. Waldhelm A, Li L. Endurance tests are the most reliable core stability related measurements. Journal of Sport and Health Science. 2012 Sep 1;1(2):121-8.

10. Carregaro RL, Coury HJ. Does reduced hamstring flexibility affect trunk and pelvic movement strategies during manual handling?. International Journal of Industrial Ergonomics. 2009 Jan 1;39(1): 115-20.

11. Fasuyi FO, Fabunmi AA, Adegoke BO. Hamstring muscle length and pelvic tilt range among individuals with and without low back pain. Journal of Bodywork and Movement Therapies. 2017 Apr 1;21(2):246-50.

12. Mierau D, Cassidy JD, Yong-Hing K. Lowback pain and straight leg raising in children and adolescents. Spine. 1989 May 1;14(5): 526-8.

13. Kujala UM, Taimela S, Oksanen A, Salminen JJ. Lumbar mobility and low back pain during adolescence: a longitudinal three-year follow-up study in athletes and controls. The American journal of sports medicine. 1997 May;25(3):363-8.
14. Esola MA, McClure PW, Fitzgerald GK, Siegler S. Analysis of lumbar spine and hip motion during forward bending in subjects with and without a history of low back pain. Spine. 1996 Jan 1;21(1):71-8.

15. Lemmink KA, Kemper HC, Greef $M H$, Rispens P, Stevens M. The validity of the sit-and-reach test and the modified sit-andreach test in middle-aged to older men and women. Research quarterly for exercise and sport. 2003 Sep 1;74(3):331-6.

16. Ayala F, de Baranda PS, Croix MD, Santonja F. Reproducibility and criterionrelated validity of the sit and reach test and toe touch test for estimating hamstring flexibility in recreationally active young adults. Physical Therapy in Sport. 2012 Nov 1;13(4):219-26.

17. Buer N, Linton SJ. Fear-avoidance beliefs and catastrophizing: occurrence and risk factor in back pain and ADL in the general population. Pain. 2002 Oct 1;99(3):485-91.

18. Hultman G, Nordin M, Saraste H, Ohlsen H. Body composition, endurance,strength, cross- sectional area, and density of MM erector spinae in men with and without low back pain. Journal of spinal disorders. 1993 Apr 1;6(2):114-23.

19. Kankaanpää M, Taimela $S$, Laaksonen $D$, Hänninen $\mathrm{O}$, Airaksinen $\mathrm{O}$. Back and hip extensor fatigability in chronic low back pain patients and controls. Archives of physical medicine and rehabilitation. 1998 Apr 1;79(4):412

20. Liu F, Jones AY, Evans K, Tsang RC, Ao L. Trunk muscle endurance in Chinese adults. Journal of back and musculoskeletal rehabilitation. 2018 Jan 1;31(4):593-602.

21. Coleman JL, Straker LM, Campbell A, Izumi $\mathrm{H}$, Smith A. Biering-Sorensen test performance of Japanese young males: comparison with other ethnicities and relationship to electromyography, nearinfrared spectroscopy and exertion ratings. Ergonomics. 2011 Jul 1;54(7):636-55.

22. Lear SA, Kohli S, Bondy GP, Tchernof A, Sniderman AD. Ethnic variation in fat and lean body mass and the association with insulin resistance. The Journal of Clinical Endocrinology \& Metabolism. 2009 Dec 1;94(12):4696-702.

23. Dawes JJ, Orr RM, Siekaniec CL, Vanderwoude AA, Pope R. Associations between anthropometric characteristics and physical performance in male law 
enforcement officers: a retrospective cohort study. Annals of occupational and environmental medicine. 2016 Dec $1 ; 28(1): 26$.

24. Correia JP, Oliveira R, Vaz JR, Silva L, Pezarat-Correia P. Trunk muscle activation, fatigue and low back pain in tennis players. Journal of science and medicine in sport. 2016 Apr 1;19(4):311-6.

25. Ferreira, Paulo H.; Ferreira, Manuela L.; Hodges, Paul W. Changes in Recruitment of the Abdominal Muscles in People With Low Back Pain, Spine: November 15, 2004 Volume 29 - Issue 22 - p 2560-2566 doi: 10.1097/01.brs.0000144410.89182.f9

26. Sutherlin MA, Gage M, Mangum LC, Hertel J, Russell S, Saliba SA, Hart JM. Changes in muscle thickness across positions on ultrasound imaging in participants with or without a history of low back pain. Journal of athletic training. 2018 Jun;53(6):553-9.

27. Rostami M, Ansari M, Noormohammadpour P, Mansournia MA, Kordi R. Ultrasound assessment of trunk muscles and back flexibility, strength and endurance in offroad cyclists with and without low back pain. Journal of back and musculoskeletal rehabilitation. 2015 Jan 1;28(4):635-44.

28. Mannion AF, Weber BR, Dvorak J, Grob D, Müntener M. Fibre type characteristics of the lumbar paraspinal muscles in normal healthy subjects and in patients with low back pain. Journal of orthopaedic research. 1997 Nov;15(6):881-7.
29. Arab AM, Nourbakhsh MR. Hamstring muscle length and lumbar lordosis in subjects with different lifestyle and work setting: Comparison between individuals with and without chronic low back pain. Journal of Back and Musculoskeletal Rehabilitation. 2014 Jan 1;27(1):63-70.

30. Mistry, Gopi \& Vyas, Neeta \& Sheth, Megha. (2014). Comparison of hamstrings flexibility in subjects with chronic low back pain versus normal individuals. Journal of Clinical \& Experimental Research. 2. 85. 10.5455/jcer.201413.

31. Hori M, Hasegawa $H$, Takasaki $H$. Comparisons of hamstring flexibility between individuals with and without low back pain: systematic review with metaanalysis. Physiotherapy Theory and Practice. 2019 Jul 19:1-24.

32. Miyamoto, Naokazu \& Hirata, Kosuke \& Kimura, Noriko \& Miyamoto-Mikami, Eri. (2017). Contributions of Hamstring Stiffness to Straight-Leg-Raise and Sit-andReach Test Scores. International Journal of Sports Medicine. 39. 10.1055/s-0043117411.

How to cite this article: Baxi HD, Sheth MS. Comparison of core endurance and hamstring flexibility of adults with and without low back pain. Int J Health Sci Res. 2021; 11(10): 220227. DOI: https://doi.org/10.52403/ijhsr. 20211029 